\title{
Correspondenzen und Erwiderungen.
}

Zur chirurgischen Behandlung der Pericarditis.

Einige Bemerkungen zum Artikel des Herrn Dr. Brentano in No. 32 dieser Wochenschrift.

Der Autor hat sich unter anderem zum Ziel gestellt, die Wahl des wichtigen Ortes zu bestimmen, wo man bei Pericarditis exsudativa operiren soll, ohne Gefahr zu laufen, das Herz zu verletzen.

Dabei sagt er: „Bis vor kurzem hat man allgemein angenommen, dass das Herz seiner Schwere entsprechend den tiefsten Punkt in der Flüssigkeit einnehme und infolge dessen der hinteren Brustwand näher liege, als der vorderen. Diese Annahme borechtigte, nebenbei bemerkt, $\mathrm{zu}$ dem Schlusse, dass das Vorhandensein pericarditischer Reibegeräusche gegen das Bestehen eines grösseren Exsudats spreche. In Wirklichkeit aber liegen die Verbältnisse wesentlich anders."

Darüber nuss ich die Bemerkung machen, dass ich mich schon seit vielen Jahren für die Frage uber die Lage des Herzens im pericardialen Exsudate in hohem Maasse interessire, ob es denn wirklich wahr sei, wio fast alle Autoren behaupten, dass das Herz innerhalb des Exsudats nach hinten und unten falle, oder ob es irgend welche andere Lage einnebme.

Um diese wichtige Frage zu entscheiden, habe ich als Ordinator der therapeutischen Abtheilung des Odessaer jüdischen Spitals während meiner 23 jährigen Wirksamkeit einc grosse Zahl von Beobachtungen an Lebenden, sowie an Obductionen zusammengestellt. Dabei habe ich mich stets überzeugt, dass das Herz bei exsudativer Pericarditis der vorderen Brustwand unmittelbar anliegt, selbst wenn keine Adhäsionen zugegen sind.

Ich unternahm im Jahre 1895 eine Reihe von Experimenten an Leichen und die gewonnenen Resultate haben die von mir aufgestellten $\mathrm{Be}$ hauptungen vollig bestätigt. Ich erklärte die Tendenz des Herzens, nach vorne und oben zu streben, durch die Elasticitat der grossen Gefásse.

Die Resultate meiner langjährigen Untersuchungen habe ich am 2. December 1895 in der Sitzung der Odessaer Aerzteversammlung mit entsprechenden Demonstrationen vorgetragen. Im Juli 1896 erschien meine Arbeit im Drucke im russischen Archiv von $\mathrm{P}_{0}$ dwissotzky sammit Autoreferat in franzosischer Sprache. Gleich darauf waren Referate erschienen in der Revue médicale No. 117, 30. September 1896. Im zweiten Bande 1897 (Heft 1-2, erschienen im Juli) ist meine Arbeit in den Mittheilungen aus den Grenzgebieten der Medicin und Chirurgie erschienen, betitelt: "Zur Frage uber Pericarditis, Klinisches und Experimentelles". In dieser Arbeit findet man genau die Lösung der Frage uber die Lage des Herzens im Exsudat, die topographischen Verhältnisse der Pleura zum Pericard und zur Brustwand und tuber die gevignetste Stelle zur Vornahme der Operation u. s. w.

Ferner sagt Herr Dr. Brentan o Folgendes: „Neuerdings hat Schaposchnik off durch Injection des Herzbeutels an der Leiche die Lage des Herzens im Exsudate zu erforschen versucht. Er kommt zu demselben Resultate, das wir an Lebenden gewonnen haben. Seine Versuche

1) Russisches Archiv für Pathologie, klinische Medicin und Bacteriologie von Podwissotzky, Kiew, II. Bd., 1.-2. Heft, Juli 1896. 
kann ich aber deshalb nicht als beweisend erachten, weil sie nach Entfernung der vorderen Brustwand gemacht sind etc." Richtiger wäre zu sagen, da Brentano'seine Beohachtungen erst jetzt veröffenflicht hat, dass er an Lebenden zu demselben Resultate gelangt ist, welches ich schon lange frther in meinen klinischen und experimentellen Studien gewonnen habe.

A uf Grund der angefuhrten Thatsachen balte ich nich berechtigt, die Priorität der Beobachtıngen an Lebenden und der experimentellen Begründungen an Leichen über die Lage des Herzens im flüssigen Exsudate fur mich in Anspruch zu nehmen. Es gereicht mir zur grossen Freude und Befriedigung, dass von solch' autoritativer Seite, wie aus der chirurgischen Abtheilung des städtischen Krankenhauses am Urban in Berlin meine Behauptıngen über die Lage des Herzens im pericarditischen Exsudate vollkommen bestätigt werden. Was nun die Behauptung des Herrn Dr. Brentano betrifft, dass meine Experinente nicht beweisend sind etc., muss ich darauf Folgendes erwidern: Herr Dr. Brentano sagt ja selbst, dass ich zu denselben Resultaten gekommen bin, wie jetzt er und Rehn an Lebenden (Berliner klinische Wochenschrift 1897, No. 20). Also entsprechen ja meine Versuche den Thatsachen und sind eo ipso beweisend. Ferner, welchen Einfluss kann denn die Entfernung der vorderen Brustwand auf die Lage des Herzens baben, welchen Umstand Brentano an meinen Versuchen beanstandet.

Nach meiner Behauptung spielt ja die Elasticität der grossen Gefässe die Hauptrolle, indem letztere das Herz nicht fallen lassen, sondern nach vorne und oben ziehen, welcher Ansicht auch Brentano zustimmt.

Am Schlusse erlaube ich mir zu betonen, dass ich in der mir zllgänglichen Litteratur nirgends eine Andeutung gefunden habe, dass Jemand vor dem Erscheinen meiner Arbeit die allgemein angenommene (falsche) Ansicht über die Lage des Herzens im pericarditischen Exsudate so kategorisch widerlegt hätte, wie ich es gethan.

Dr. B. Schaposchnikoff (Odessa). 